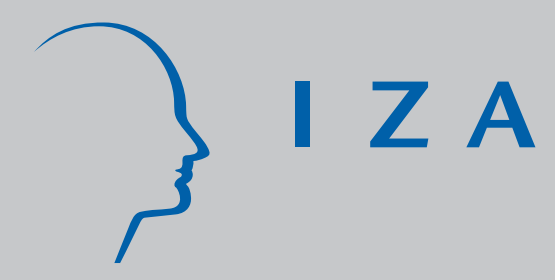

IZA DP No. 1934

Head-content or Headcount?

Short-term Skilled Labour Movements as a Source of Growth

Massimiliano Tani

J anuary 2006 


\title{
Head-content or Headcount? \\ Short-term Skilled Labour Movements \\ as a Source of Growth
}

\author{
Massimiliano Tani \\ UNSW@ADFA and IZA
}

Discussion Paper No. 1934

January 2006

IZA

P.O. Box 7240

53072 Bonn

Germany

\author{
Phone: +49-228-3894-0 \\ Fax: +49-228-3894-180 \\ Email: iza@iza.org
}

\begin{abstract}
Any opinions expressed here are those of the author(s) and not those of the institute. Research disseminated by IZA may include views on policy, but the institute itself takes no institutional policy positions.

The Institute for the Study of Labor (IZA) in Bonn is a local and virtual international research center and a place of communication between science, politics and business. IZA is an independent nonprofit company supported by Deutsche Post World Net. The center is associated with the University of Bonn and offers a stimulating research environment through its research networks, research support, and visitors and doctoral programs. IZA engages in (i) original and internationally competitive research in all fields of labor economics, (ii) development of policy concepts, and (iii) dissemination of research results and concepts to the interested public.
\end{abstract}

IZA Discussion Papers often represent preliminary work and are circulated to encourage discussion. Citation of such a paper should account for its provisional character. A revised version may be available directly from the author. 


\section{ABSTRACT \\ Head-content or Headcount? \\ Short-term Skilled Labour Movements as a Source of Growth*}

This paper contributes a theoretical model to study the effects of short-term movements of skilled labour on a country's economic growth. As traditional migration models emphasise the long-term effects of migration on factor endowments, they typically omit the analysis of gross labour flows. Gross flows however capture the volume of interactions and knowledge exchanges between workers living in different countries, which in turn affect the stock of knowledge available to their places of residences, and hence their ability to innovate and grow. A simulation based on available US, British and Australian data on international business visits reveals that short-term skilled labour movements have a positive and not insignificant effect on growth.

JEL Classification: F2, J6

Keywords: international migration, temporary labour movements, skilled labour, economic growth

Corresponding author:

Massimiliano Tani

School of Business

The University of New South Wales @ ADFA

Northcott Drive

Campbell, ACT 2612

Australia

Email: m.tani@adfa.edu.au

\footnotetext{
* I benefited from comments and suggestions on earlier versions of this paper from S. Dowrick, $\mathrm{H}$. Prior, K. Sharpe, A. Ichino, G. Femminis, U. Ben-Zion and participants at the SOLE/EALE conference (San Francisco) and at seminars held at IZA (Bonn), Universita' Cattolica (Milan), and the Robert Schumann Centre (Florence). I thank IZA and the Department of Economics of the European University Institute (Florence) for the kind hospitality.
} 


\section{Introduction}

It is known that skilled labour is a significant source of economic growth as it creates new knowledge and innovation, and that countries use migration policies to attract it. Both theoretical and empirical studies have shown that a country's endogenous sources of growth include its endowment of skilled labour (e.g. Dowrick, 2002; Wolff, 2000). Skilled workers are instrumental in generating new knowledge (e.g. Lucas, 1988; Romer, 1986 and 1990), and in absorbing new ideas that are continuously developed around the world (e.g. Dosi, 1988, Cohen and Levinthal, 1989). Given the strategic importance of these functions, skilled immigrants are generally welcomed the world over, typically through policies that favour their permanent settlement (e.g. Borjas, 1989; Zimmermann, 2005).

One characteristic of existing work is the focus on skilled labour movements that have a long-term or permanent nature. As a result, their economic impact is studied using net labour inflows. This approach however excludes work-related movements that last for a short period of time. Although these labour flows are conventionally reported as "visits" in the statistics of international organisations such as the United Nations and national governments, they ought to be part of the analysis of skilled labour migration for at least two reasons. First, they are common among highly skilled workers (e.g. OECD, 2002), and there is evidence of their increasing substitution of longer-term forms of migration (e.g. Salt, 1992).

Second, the focus on net balances does not really measure the movement of ideas and knowledge associated with the movement of people ('head-content'), as it only accounts for the net change in a country's endowment of labour ('headcount'). Since 
the contribution to knowledge of incoming and outgoing visitors and residents is unlikely to be identical, the study of gross rather than net flows of work-related movements is also needed for a more comprehensive picture of international skilled labour flows.

Gross flows are in fact a better proxy than net flows for measuring the head-content associated with short-term labour movements, as they give a measure of the volume of interactions, and hence the potential knowledge exchanges and development, between workers of different countries. Although the idea that short-term labour movements affect a country's stock of knowledge is not new (e.g. Rogers, 1995), the role of migrants is studied only insofar as they facilitate an international transfer of technology and information. Less attention has been devoted to mobility per se as a characteristic of migration and a constituent element in the formation of knowledge.

This paper contributes a theoretical model that captures the effect of labour movements on both factor endowments and the stock of knowledge. One result is that higher growth can be achieved through higher international labour mobility ('churning'), even if there are no permanent changes in labour endowments among countries. Nations that find it difficult or impossible to attract skilled labour on a permanent basis may therefore benefit from the growth effects of short-term skilled labour movements.

The rest of the paper is organised as follows: Section 2 reviews the definitional issues and theoretical approaches related to temporary labour movements. Section 3 develops the theoretical model. Section 4 presents the results of a simulation based on 
US, UK, and Australian data on international business travel. Section 5 discusses some policy implications and concludes.

\section{Literature}

\section{Definitional issues}

Broadly speaking temporary labour movements are work-related movements that last for only a short period of time, though there is no internationally agreed definition about how short their time span should be. The United Nations and the International Monetary Fund use a 12-month convention before recording non-residents as migrants rather than visitors, and accounting for compensation earned abroad as income for the host rather than the sending country. Other institutions use different conventions. The World Trade Organisation applies the word temporary to mean up to 90 days for certain labour movements and up to 5 years for other movements of workers.

This heterogeneity of conventions is reflected in the legal and statistical treatment of various forms of temporary movement, and the extent of their economic analysis. Some movements, such as seasonal migration, circular movements, international commuting, and guest-workers programs, are viewed as a form of migration that is clearly economically motivated. These labour flows are regulated by a country's employment and migration laws, and tend to be relatively well documented (e.g. OECD, 1994). Their economic effects are therefore investigated in some detail, particularly with regard to labour markets and welfare for both countries of origin and destination (e.g. Priore, 1979; Gould, 1980; Dustmann, 2000; Constant and Zimmermann, 2003). 
In contrast, other temporary movements like international business trips, temporary assignments, and short intra-company transfers (let alone work-related exchanges that do not involve a physical transfer such as videoconferencing and telecommuting) are more difficult to classify and interpret as a genuine form of labour migration. Part of the problem is related to data. Information is generally unavailable or confidential for transfers and assignments, or it is of limited use for economic analysis. International passengers surveys provide a large amount of statistics on the in- and out-bound flows of temporary visitors to a number of countries, the length of trip, and the main reason for travel (e.g. tourism, business, conference, education, settlement), but typically do not report the exact motivation for doing so. As a result, marketing and follow up trips facilitating an international transaction cannot be distinguished from business visits aimed at transferring or developing specialist knowledge in a foreign country.

A few studies suggest that international business trips are a form of labour migration, though they generally confine their analysis to air travel, as it is the most common way to carry out trips beyond a certain distance or to/from countries separated by natural barriers, like Australia, the UK or the US. Business trips are associated with an exchange of skills and knowledge, whose effects last well beyond the duration of business visits (e.g. Slaughter, 2000; Wood, 2001; Hansson, 2001). With improved communication and transportation facilities, the substitution of long-term resettlement with business travel has also emerged, as firms concentrate key managerial and technical skills in a single location and deploy such resources to peripheral areas through short-term trips (e.g. Ohmae, 1990; Moss-Kanter, 1995). 
The view that business travel is not a form of labour migration is generally based on the argument that it provides ancillary services that facilitate the international exchange of goods or services (e.g. accompanying exported goods). Hence it should be considered as a component of the international trade of commodities and services. The World Trade Organisation, in the General Agreement for the Trade of Services Mode 4 ('GATS'), suggests that if an international labour movement occurs as a result of a contract for the provision of services then it should be treated as a service (contract for services), and be governed by its legislation, but if it arises from an employment contract it should be viewed as a labour movement (contract of services), and be regulated by domestic migration laws.

Unfortunately the distinction between contracts for and of service is practically impossible to apply: the legal categories are not mutually excludable ${ }^{1}$ and they do not take into account alternative ways in which an identical service can be delivered ${ }^{2}$. In practice the GATS Mode 4, which aims at reducing the barriers to the international movement of services and related labour movements, still allows each country to impose quotas and other restrictions ${ }^{3}$ on the same flows it sets to liberalise, implicitly supporting that these labour movements can be viewed, after all, as a form of labour migration.

\footnotetext{
${ }^{1}$ For example, the test applied by the tax law in the UK to separate a contractor (contract for services) from an employee (contract of services) is wider than the corresponding tests applied by industrial or patent law.

2 The GATS makes no provisions for either self-employed temporary migrants or foreign citizens temporarily employed by a domestic company. Hence identical services delivered by the same person under an employment contract with a local company or a services contract with a foreign provider may be treated differently (e.g. Charnovitz, 2002).

3 These include (among others): minimum educational qualification level and professional experience, determined periods of prior employment, economic needs tests giving preference to domestic workers, and the very definition of 'temporary'.
} 


\section{Theoretical approach}

Two theoretical approaches are commonly applied in the study of temporary labour movements. In the first labour movements are treated as a change in labour (or skill) supply in both countries of origin and destination (e.g. Barro and Sala-i-Martin, 1995; OECD, 2002). This interpretation reflects the traditional economic perspective of viewing labour as a factor of production (headcount) (e.g. World Bank, 1995). Under this approach temporary and permanent migrants differ for a number of reasons, but not in their economic effects. As pointed out by Winters (2002), temporary labour migration "has none of the cultural, social or political dimensions that are associated with international migration because it explicitly does not entail shifts in residence. However, its direct economic consequences can be thought of as those of migration. Workers enter a country temporarily to carry out particular jobs and thus labour inputs in one economy are reduced while those in another are increased" (p.6). This interpretative framework has raised some criticisms for its over-simplification of the creative abilities of humans (and migrants), which are reduced to an input (Simon, 1989).

In the second group of studies short-term migrants are treated as agents in forming and diffusing knowledge. Migrants enhance knowledge in both countries of origin and destination by facilitating technological spill-overs and contributing new ideas (headcontent). The contribution of permanent and temporary migrants normally differs, as it also depends on the frequency of movement. Existing work principally focuses on the characteristics of the innovation process (e.g. Dosi et al., 1988; Cohen and Levinthal, 1989), exploring the role played by temporary migrants insofar as they can help a country to absorb and transfer new technology and information (e.g. Leahy and 
Neary, 2003). Typically the role of mobility in the formation of knowledge is not explored. In addition, these studies do not offer a formal treatment of the mechanisms through which temporary labour movements affect growth. This paper combines both approaches in a single theoretical growth model.

\section{The theoretical model}

The neoclassical growth framework of Solow and Swan, as modelled by Barro and Sala-i-Martin (1995 - 'BS') is used a starting point. Temporary migrants are introduced under the assumptions that they affect the economy through two distinct mechanisms. First, as a change in labour input in both countries of origin and destination, since skills are embodied in, and hence move with, the temporary migrant (embodied effect). This effect is proportional to the net flows of migrants.

Second, as a contribution to knowledge from participating in the flow of ideas and technologies continuously developed around the world. This effect is modelled as an externality due to labour mobility per se: the higher the number of workers exchanging information and ideas and the higher the frequency of their movements, the higher the knowledge contribution from in- and outbound visitors, and vice-versa (disembodied effect). Empirical support for this modelling choice is given by the high correlation between short-term gross labour flows and multifactor productivity (Figure 1). The disembodied effect operates differently for permanent and temporary migrants: the knowledge contribution of the former is high after arrival, but it fades as time goes on, assuming no further movement. For the latter it is directly related to the frequency of their international movements. 
Consider a country producing with the production function:

$$
Y_{t}=F\left(K_{t}, A_{t} L_{t}\right) c\left(\frac{A V_{I t}}{L_{t}}, \frac{A V_{O t}}{L_{t}}, \frac{K_{t}}{A_{t} L_{t}}\right)
$$

where $Y_{t}$ is the GDP at time $t, F$ is a monotonic function exhibiting constant returns to scale, $K_{t}$ indicates capital in its broad sense (physical and human), $A_{t}$ is a labouraugmenting technology, and $L_{t}$ indicates the country’s labour supply.

$c\left(\frac{A V_{I t}}{L_{t}}, \frac{A V_{O t}}{L_{t}}, \frac{K_{t}}{A_{t} L_{t}}\right)$ is a function representing the externality associated with the flows of effective incoming $\left(A V_{I t}\right)$ and outgoing $\left(A V_{O t}\right)$ 'equivalent workers' due to temporary labour movements, respectively, as a proportion of the country's labour force $L_{t}$ and the amount of capital per effective worker $\frac{K_{t}}{A_{t} L_{t}}$. The calculation of an equivalent worker is the product of number of visits and their average length divided by 250 , which corresponds to the average number of business days in a year (e.g. Anderson, 2002). In and out-flows of temporary migrants are by assumption proportional to the labour force:

$$
\begin{aligned}
& A_{t} V_{I t}=\lambda_{t} L_{t} \\
& A_{t} V_{O t}=\theta_{t} L_{t}
\end{aligned}
$$

where $\lambda_{t}$ and $\theta_{t}$ are positive parameters. By assumption $\partial c(.) / \partial \lambda_{t}>0$ and $\partial c(.) / \partial \theta_{t}>0$, so that each new addition of disembodied knowledge improves domestic production. Making $c($.$) dependent on \frac{K_{t}}{A_{t} L_{t}}$ reflects that participation in knowledge sharing is easier when infrastructure is good (e.g. Gaspar and Glaeser, 1998). 
As in BS, $\partial Y_{t} / \partial K_{t}>0$ and $\partial Y_{t} / \partial L_{t}>0$ but $\partial^{2} Y_{t} / \partial K_{t}^{2}<0$ and $\partial^{2} Y_{t} / \partial L_{t}^{2}<0$. Trade with the rest of the world occurs only through international labour movements. Capital moves internationally with labour migrants. Commodity trade is not permitted.

The intensive form of (1) is:

$$
\frac{Y_{t}}{A_{t} L_{t}}=y_{t}=f\left(\frac{K_{t}}{A_{t} L_{t}}, 1\right) c\left(\lambda_{t}, \theta_{t}, k_{t}\right)=f\left(k_{t}\right) c\left(\lambda_{t}, \theta_{t}, k_{t}\right)
$$

where $k_{t}=K_{t} / A_{t} L_{t}$.

Labour supply in the home country is the sum of:

(i) native labour, which grows at a constant exogenous annual rate $n$;

(ii) the net inflow of permanent migrants into the country $M_{t} . M_{t}>0$ corresponds to net immigration. For simplicity, each migrant carries an identical quantity of physical and human capital $\kappa$.

(iii) the net flow of equivalent workers $\left(\lambda_{t}-\theta_{t}\right) L_{t}$. Empirical evidence ${ }^{4}$ suggests that in- and outward temporary migrants have similar levels of capital $\varphi$.

The total domestic labour force grows at:

$$
\frac{\dot{L}_{t}}{L_{t}}=n_{t}+m_{t}+\lambda_{t}-\theta_{t}
$$

where the dot indicates a change over time, $m_{t} \equiv M_{t} / L_{t}$, and $\left(\lambda_{t}-\theta_{t}\right)$ are the net permanent and temporary migration rates, respectively.

\footnotetext{
4 Data on European, US and Australian business trips suggests that travellers have similar skill levels, based on occupational profiles (e.g. IATS, 1988; Anderson, 2002; Tani, 2003).
} 
As in BS, permanent migrants are sensitive to the wage level paid in the host country so that $m_{t}=m\left(k_{t}\right), m^{\prime}>0$, and $m^{\prime \prime}<0$. Treating $\lambda_{t}$ and $\theta_{t}$ as functions of the level of economic activity is perhaps more realistic, but using $\lambda_{t}=\lambda\left(k_{t}\right)$ and $\theta_{t}=\theta\left(k_{t}\right)$ raises the complexity of the solutions without modifying their substance, and it is not pursued further.

By definition the stock of human and physical capital grows annually by:

$$
\dot{K}_{t}=s F\left(K_{t}, A_{t} L_{t}\right) c\left(\lambda_{t}, \theta_{t}, k_{t}\right)-\delta K_{t}+\kappa_{t} M_{t}+\varphi_{t} L_{t}\left(\lambda_{t}-\theta_{t}\right)
$$

where $s$ is a positive constant representing the country's exogenous rate of investment as a proportion of GDP, $\delta$ is a positive constant reflecting the annual depreciation rate of physical and human capital, and $\kappa_{t} M_{t}$ and $\varphi_{t} L_{t}\left(\lambda_{t}-\theta_{t}\right)$ are the amount of capital carried by permanent and temporary migrants, respectively. The latter are likely to carry predominantly human capital. Rearranging the expression in terms of change in capital yields:

$$
\dot{k}_{t}=s f\left(k_{t}\right) c\left(\lambda_{t}, \theta_{t}, k_{t}\right)-(x+n+\delta) k_{t}-m\left(k_{t}\right)\left(k_{t}-\hat{\kappa}_{t}\right)-\left(\lambda_{t}-\theta_{t}\right)\left(k_{t}-\hat{\varphi}_{t}\right)
$$

where $s f\left(k_{t}\right) c\left(\lambda_{t}, \theta_{t}, k_{t}\right)$ is the change in the capital per effective worker arising from new investments and the externality of the disembodied effect due to temporary labour movements. This term (capital accumulation - 'KA') is positive, and its value depends directly on $k_{t}$, even though it can not be established apriori. The sign of $\partial\left(s f() c.(.) / k_{t}\right) d k_{t}=s\left[k_{t}\left(f^{\prime}() c.()+.c^{\prime}() f.().\right)-f() c.().\right] / k_{t}^{2}$ is indeterminate: $k_{t}\left(f^{\prime}() c.()+\right.$. $\left.c^{\prime}() f.().\right)$ is positive while $-f() c.($.$) is negative. Capital accumulation grows with the$ capital per effective worker ratio $k_{t}$ whenever the sum of the marginal productivity of labour $\left(k_{t} f^{\prime}()-.f().\right)$ and the marginal value of the externality $k_{t} c^{\prime}() f.(.) / c($.$) is positive,$ 
and vice-versa. When $c().\left(k_{t} f^{\prime}()-.f().\right)=k_{t} c^{\prime}() f.($.$) then capital accumulation becomes$ independent of $k_{t}$. Hence, despite capital's diminishing returns, capital accumulation can be an increasing, decreasing or constant function of capital per effective worker.

The term $\left[(x+n+\delta)+m\left(k_{t}\right)\left(k_{t}-\hat{\kappa}_{t}\right)+\left(\lambda_{t}-\theta_{t}\right)\left(k_{t}-\hat{\varphi}_{t}\right)\right]$ represents the depreciation rate of capital per effective worker (capital depletion - 'KD'). The parameters $\hat{\kappa}_{t}$ and $\hat{\varphi}_{t}$ indicate the effective human and physical capital brought by permanent and temporary migrants, respectively, i.e. $\hat{\kappa}_{t}=A_{t} \kappa_{t}$ and $\hat{\varphi}_{t}=A_{t} \varphi_{t}$.

The impact of temporary migration on the steady state and growth can be either positive or negative depending on whether there is a net in- or outflow of migrants, and their capital content relative to natives. In general, net inflows of unskilled migrants carrying raise capital depletion. A similar effect occurs when there are net outflows of highly skilled migrants. Table 1 summarises the possible combinations of permanent and temporary migration raising the capital per effective labour ratio.

The growth rate of income per effective labour is obtained from the path describing the corresponding growth rate of the capital stock. Combining equations (1) and (5) and transforming the variables in the intensive form yields:

$\dot{y}_{t} / y_{t}=\gamma_{y, t}=f^{\prime}\left(k_{t}\right) c\left(\lambda_{t}, \theta_{t}, k_{t}\right) \dot{k} / f\left(k_{t}\right)=\left[k_{t} f^{\prime}\left(k_{t}\right) c\left(\lambda_{t}, \theta_{t}, k_{t}\right) / f\left(k_{t}\right)\right] \gamma_{k, t}$

where the term inside the square brackets represents the share of income belonging to capital owners. When the production function (1) takes the form of a Cobb-Douglas, the capital share is constant and the growth rate of GDP per effective worker $\gamma_{y, t}$ mimics the behaviour of the growth rate of capital per effective worker $\gamma_{k, t}=\dot{k}_{t} / k_{t}$. 
Steady state and transition dynamics

The steady state is reached when:

$$
\gamma_{k, t}=s f\left(k_{t}\right) c\left(\lambda_{t}, \theta_{t}, k_{t}\right) / k_{t}-(x+n+\delta)-m\left(k_{t}\right)\left(1-\hat{\kappa}_{t} / k_{t}\right)-\left(\lambda_{t}-\theta_{t}\right)\left(1-\hat{\varphi}_{t} / k_{t}\right)=0
$$

Unlike the neoclassical model where there is a unique stable steady state that depends only on the value of $k_{t}$, the steady state here depends on the signs and values of the migration parameters $m\left(k_{t}\right),\left(\lambda_{t}-\theta_{t}\right),\left(1-\hat{\kappa}_{t} / k_{t}\right),\left(1-\hat{\varphi}_{t} / k_{t}\right)$, as well as the functional form of the externality $c\left(\lambda_{t}, \theta_{t}, k_{t}\right)$.

Consider as an example the case where there is only a net inflow of unskilled permanent migrants and no temporary migration, and let $f\left(k_{t}\right)=k_{t}^{\alpha}$ with $\alpha<1$. As illustrated in Figure 2, which is based on Figure 9.2 in BS, capital accumulation is shown with the positive and decreasing sloped line $K A_{0}$ while capital depletion is indicated with the positively sloped line $K D_{0}$. The vertical distance between the two lines is the growth rate of capital per effective worker $\gamma_{k, t}$, while their intersection is the steady state $\mathbf{1}$, which corresponds to the steady state capital per effective labour ratio $k^{*}$.

Let now introduce short-term labour migration assume a net outflow of highly skilled workers, so that $\left(\lambda_{t}-\theta_{t}\right)<0$ and $\hat{\varphi}_{t}>k_{t}$. The corresponding embodied effect reduces capital per effective labour as $\hat{\varphi}_{t}>k_{t}$, and raises capital depletion to the dotted line $K D_{1}$ in Figure 1 . This has a negative impact on growth, and shifts the steady state towards point 2 . 
The disembodied effect raises the nation's stock of knowledge, and hence capital accumulation to the line $K A_{1}$. The new steady state occurs at point $\mathbf{3}$, which illustrates the case when the disembodied effect is larger than the embodied effect. As a result growth has increased relative to the initial steady state $k^{*}$ even though the country has suffered a temporary loss of skilled domestic labour.

\section{Endogenous growth}

An interesting feature of this model is the possible emergence of endogenous growth, which occurs when the disembodied effect on capital accumulation is so large that capital accumulation and depletion never intersect each other. Under these circumstances countries with lower capital per effective labour ratio may never catch up with richer countries, unlike the original Solow-Swan model. The condition for endogenous growth is $s k_{t}^{\alpha} c()>.(x+n+\delta) k_{t}+m\left(k_{t}\right)\left(k_{t}-\hat{\kappa}_{t}\right)+\left(\lambda_{t}-\theta_{t}\right)\left(k_{t}-\hat{\varphi}_{t}\right)$ for each value of $k_{t}$.

\section{Implications for migration policy}

Using equation (6) a change in the net permanent migration rate $\partial \gamma_{k, t} / \partial m\left(k_{t}\right)=-$ $m^{\prime}\left(k_{t}\right)\left(1-\hat{\kappa}_{t} / k_{t}\right)$ is coeteris paribus negative when $\hat{\kappa}_{t}<k_{t}$ and $m\left(k_{t}\right)>0$, and positive in the opposite case. Permanent immigration reduces the growth when immigrants have less capital than natives, and vice-versa, as in BS.

A positive shock to either $\theta_{t}$ or $\lambda_{t}$ enhances growth in the home country when temporary migrants are as or more skilled than domestic workers. The gross inflow of highly skilled foreign visitors always leads to growth (in this case $\partial \gamma_{k, t} / \partial \theta_{t}=$ $\left.s f\left(k_{t}\right) C^{\prime}\left(\lambda_{t}, \theta_{t}, k_{t}\right) / k_{t}-\left(1-\hat{\varphi}_{t} / k_{t}\right)>0\right)$, while the outflow of domestic labour has a 
positive net effect only when the disembodied effect $\left(s f\left(k_{t}\right) c^{\prime}\left(\lambda_{t}, \theta_{t}, k_{t}\right) / k_{t}\right)$ is larger than the corresponding embodied effect.

In this model temporary migrants can compensate a reduction in the capital per effective labour ratio caused by a net inflow of unskilled permanent migrants. Whether or not this occurs ultimately depends on empirical values (Table 1). The argument worth noting is that temporary migration can alleviate phenomena of brain drain, or net inflows of unskilled labour.

Another feature of the model is the prediction that even identical gross in- and outflows of temporary migrants $\left(\lambda_{t}=\theta_{t}\right)$ lead to growth. This result emerges as a zero net inflow of temporary migrants still makes a positive contribution to knowledge and growth. In this case the contribution to knowledge depends only on the frequency of travel between workers living in different countries. The higher is churning, the higher is the disembodied effect.

\section{A simulation}

This section simulates the impact of temporary migrants on a country's growth rate. The calculation has only illustrative purposes aimed at highlighting the possible growth effects of short-term migration as proxied by international business visits. No use of econometric techniques is made, partly to overcome the difficulty surrounding the estimation of $s f\left(k_{t}\right) c\left(\lambda_{t}, \theta_{t}, k_{t}\right)$ with the available data (this is beyond the scope of the paper), and partly because the migration parameter $\left(\lambda_{t,-} \theta_{t}\right)\left(k_{t}-\hat{\varphi}_{t}\right)$ is a number that can be obtained with no recourse to statistical inference. Only available data are used for the empirical exercise as well as estimates from previous work. 
The calculation is performed on US, British, and Australian data for the year 1997 reported in Table 2. As in BS (p.292) it is assumed that temporary migrants carry only human capital so that this ratio can be used as a proxy for the term $\hat{\varphi}_{t} / k_{t}$ in equation (6) expressed as a growth rate $\dot{k}_{t} / k_{t}$. Despite differences in collection method and other limitations of the data, the figures in the second and third columns in Table 2 indicate that these three countries are net exporters of skilled labour through international business travel ${ }^{5}$, as the inflows of equivalent workers outweigh the corresponding outflows, and the value of $\hat{\varphi}_{t} / k_{t}$ is greater than unit. As a result, for each country the embodied effect of temporary migration is expected to raise capital depletion and have a negative impact on the growth rate.

Table 3 shows the estimates of the embodied and disembodied effects of temporary migration on growth. The embodied effect in the first column is calculated as the product of the difference between gross inflows and outflows of equivalent workers, the term $\left(1-\hat{\varphi}_{t} / k_{t}\right)$, and two adjustments to correct for (i) the measurement of $\hat{\varphi} / k_{t}$, which captures only human capital, and (ii) the need to rescale the result in terms of growth rate of GDP rather than capital per effective worker, according to equation (7). Similarly to BS, it is assumed that in each country the ratio of human to total capital in the domestic economy of is $5 / 8$ and that the share of capital in each country's total income is $1 / 3$ (p.292). As a result, the embodied effect on GDP growth for the US in

\footnotetext{
5 The volume of business trips for the UK seems excessively large, as it represents a quarter of the country's employment. However, given the geographic proximity of the UK to continental Europe, it is likely that the figure reported reflects frequent travels and not only a high volume of travellers. This suspicion is somewhat supported by the lower average number of days of each visit (4.7 days for incoming and 6.1 for outgoing travellers, respectively), relative to those of the US (12.2 and 13.3) and Australia (14.1 and 29.5).
} 
1997 shown in the top left column of Table 3 is calculated as: $-(0.009-0.019) \times(1-$ $2.32) \times(5 / 8) \times(1 / 3)=-0.275 \%$.

The second column of Table 3 shows the disembodied effect. The strategy used follows the assumption that its effect is identical to a higher expenditure in R\&D. By so doing the disembodied effect can be calculated as the product of the gross flow of equivalent workers and the social return of $R \& D$, for which a consensus estimate is 50\% (e.g. OECD, 2000; Dowrick, 2002). The result obtained is further adjusted by 1/3 (or 8 hours per day) to transform the gross flows of equivalent workers in terms of efficiency units of labour.

The third column of Table 3 reports the net impact of business travel on the US, UK and Australian growth rates for 1997, respectively, calculated as the sum of embodied and disembodied effects. Temporary skilled labour migration emerges as having a small but non-negligible positive effect on growth.

\section{Conclusion}

This paper suggests that migration statistics under-estimate the true extent of international skilled labour movements because they do not account for the flows of workers that thanks to modern means of transportation can move across borders without changing residence. These flows are relevant because of their skill composition, relative magnitude, and potential contribution to the stock of knowledge available to a country. One feature of the model is the prediction that growth can occur even when net flow of migrants is nil, as a country’ ability to accumulate capital 
depends also on the gross flows of ideas accessed through short-term international labour movements.

\section{References}

Anderson, E. (2002). "Skilled Worker Mobility and International Inequality". Unpublished mimeo, University of Sussex.

Barro, R.J. and Sala-I-Martin, X. (1995). Economic Growth. New York: McGrawHill.

Borjas, G.J. (1989). 'Economic Theory and International Migration'. International Migration Review, 23(3), 457-483.

Charnovitz, S. (2002). "WTO Norms on International Migration”. Paper presented at the IOM Workshop on Existing International Migration Law Norms, April $30^{\text {th }}$, Geneva.

Cohen, W. and Levinthal, D. (1989). "Innovation and Learning: the Two Faces of R\&D”. The Economic Journal, 99(397), 569-596.

Constant, A. and K.F. Zimmermann (2003). Circular Movements and Time Away from the Home Country, IZA Discussion Papers 960, December.

Dosi, G. et al. (eds) (1988). Technical Change and Economic Theory, Maastricht Economic Research Institute on Innovation and Technology (MERIT), International Federation of Institutes for Advanced Study (IFIAS) Research Series, no. 6. London and New York: Pinter.

Dowrick, S. (2002). “Ideas and Education: Level of Growth Effects?”. National Bureau of Economic Research Working Paper 9709.

Dustmann, C. (2000). “Temporary Migration and Economic Assimilation”, Swedish Economic Policy Review, 7, 213-244.

Eurostat (2002). Labour Force Survey (extraction). Luxembourg: Eurostat.

Hansson, P. (2001). "Skill upgrading and Production Transfer within Swedish Multinationals in the 1990s". Unpublished mimeo, Trade Union Institute for Economic Research, January.

Keesing, D.B. (1965). "Labor Skills and International Trade: Evaluating Many Trade Flows with a Single Measuring Device”. Review of Economics and Statistics, 47, 287294. 
International Air Travel Survey (IATS) (1988). The European Frequent Business Traveller. Henley on Thames: European Data and Research Limited.

Leahy, D. and Neary, P. (2003). "Absorptive Capacity, R\&D Spillovers and Public Policy”. Unpublished mimeo, University College Dublin.

Lucas, R. (1988). 'On the Mechanics of Economic Development', Journal of Monetary Economics, 22(1), 3-42.

Moss Kanter, R. (1995). World Class. New York: Simon \& Shuster.

Office of National Statistics (1999). Travel Trends. London: Office of National Statistics.

Ohmae, K. (1990). The Borderless World. London: Harper Business.

Organisation for Economic Co-operation and Development (OECD) (2000). Knowledge, Technology and Economic Growth: Recent Evidence from OECD Countries. Paris: OECD.

Organisation for Economic Co-operation and Development (OECD) (2002). International Mobility of the Highly Skilled. Paris: OECD.

Rogers, M. (1995). International Knowledge Spill-Overs: A Cross-Country Study. In Steve Dowrick (ed), Economic Approaches to Innovation. Aldershot, UK and Brookfield, US: Edward Elgar Publications.

Romer, P.R. (1986). 'Increasing Returns and Long-Run Growth’. Journal of Political Economy, 94(5), 1002-1037.

Romer, P.R. (1990). 'Endogenous Technological Change'. Journal of Political Economy, 98(5), S71-S101.

Salt, J. (1992). "Migration Processes among the Highly Skilled in Europe". International Migration Review, 26(2), 484-505.

Simon, J. (1989). The Economic Consequences of Immigration. Oxford and Cambridge, MA: Blackwell in association with The Cato Institute.

Slaughter, M. (2000). "Production Transfer within Multinational Enterprises and American Wages”. Journal of International Economics 50, 449.

Tani, M. (2003). “International Business Travel and Australia Skills’ Endowment”. Agenda, 10(3), 248-259.

Winters, L.A. (2002). “The Economic Implications of Liberalising Mode 4 Trade”. Joint WTO-World Bank Symposium on the Movement of Natural Persons (Mode 4) Under the GATS, WTO Geneva, 11-12 April 2002. 
Wolff, Edward N. (2000). 'Human Capital Investment and Economic Growth: Exploring the Macro-Links'. Structural Change and Economic Dynamics, 11(4), 433472.

Wood, A. (2001). "Globalisation and Wage Inequalities: A Synthesis of Three Theories”. Weltwirtschaflisches Archiv, 138(1), 54-82.

World Bank (1995). World Development Report 1995: Workers in an Integrating World. Washington: The World Bank.

Zimmermann, K.F. (2005). “European Labour Mobility: Challenges and Potentials”, De Economist, 153(4), 1-26. 
Table 1 Permanent and Temporary Migration Mix Leading to an INCREASE OF THE CAPITAL PER EFFECTIVE LAbour Ratio IN THE HoMe COUNTRY

\begin{tabular}{|c|c|c|c|c|c|}
\hline & & & & & \\
\hline & & \multicolumn{4}{|c|}{ Skill Composition } \\
\hline & & $\begin{array}{c}\hat{\kappa}_{t}<\mathbf{k}_{\mathbf{t}} \\
\text { and } \\
\hat{\varphi}_{t}<\mathbf{k}_{\mathbf{t}}\end{array}$ & $\begin{array}{c}\hat{\kappa}_{t}>\mathbf{k}_{\mathbf{t}} \\
\text { and } \\
\hat{\varphi}_{t}<\mathbf{k}_{\mathbf{t}}\end{array}$ & $\begin{array}{c}\hat{\kappa}_{t}<\mathbf{k}_{\mathbf{t}} \\
\text { and } \\
\hat{\varphi}_{t}>\mathbf{k}_{\mathbf{t}}\end{array}$ & $\begin{array}{c}\hat{\kappa}_{t}>\mathbf{k}_{\mathbf{t}} \\
\text { and } \\
\hat{\varphi}_{t}>\mathbf{k}_{\mathbf{t}}\end{array}$ \\
\hline \multirow{4}{*}{ 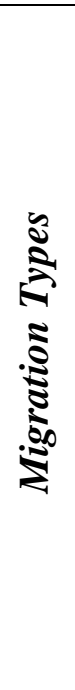 } & $\begin{array}{c}m\left(k_{t}\right)>0 \\
\text { and } \\
\lambda_{t}-\theta_{t}>0\end{array}$ & Never & $\begin{array}{c}m\left(k_{t}\right)(1- \\
\left.\hat{\kappa}_{t} / k_{t}\right)>\left(\lambda_{t}-\right. \\
\left.\theta_{t}\right)\left(1-\hat{\varphi}_{t} / k_{t}\right)\end{array}$ & $\begin{array}{c}m\left(k_{t}\right)(1- \\
\left.\hat{\kappa}_{t} / k_{t}\right)<\left(\lambda_{t}-\right. \\
\left.\theta_{t}\right)\left(1-\hat{\varphi}_{t} / k_{t}\right)\end{array}$ & Always \\
\hline & $\begin{array}{c}m\left(k_{t}\right)<0 \\
\text { and } \\
\lambda_{t}-\theta_{t}>0\end{array}$ & $\begin{array}{c}m\left(k_{t}\right)(1- \\
\left.\hat{\kappa}_{t} / k_{t}\right)>\left(\lambda_{t}-\right. \\
\left.\theta_{t}\right)\left(1-\hat{\varphi}_{t} / k_{t}\right)\end{array}$ & Never & Always & $\begin{array}{c}m\left(k_{t}\right)(1- \\
\left.\hat{\kappa}_{t} / k_{t}\right)<\left(\lambda_{t}-\right. \\
\left.\theta_{t}\right)\left(1-\hat{\varphi}_{t} / k_{t}\right)\end{array}$ \\
\hline & $\begin{array}{c}m\left(k_{t}\right)>0 \\
\text { and } \\
\lambda_{t}-\theta_{t}<0\end{array}$ & $\begin{array}{c}m\left(k_{t}\right)(1- \\
\left.\hat{\kappa}_{t} / k_{t}\right)<\left(\lambda_{t}-\right. \\
\left.\theta_{t}\right)\left(1-\hat{\varphi}_{t} / k_{t}\right)\end{array}$ & Always & Never & $\begin{array}{c}m\left(k_{t}\right)(1- \\
\left.\hat{\kappa}_{t} / k_{t}\right)>\left(\lambda_{t}-\right. \\
\left.\theta_{t}\right)\left(1-\hat{\varphi}_{t} / k_{t}\right)\end{array}$ \\
\hline & $\begin{array}{c}m\left(k_{t}\right)<0 \\
\text { and } \\
\lambda_{t}-\theta_{t}<0\end{array}$ & Always & $\begin{array}{c}m\left(k_{t}\right)(1- \\
\left.\hat{\kappa}_{t} / k_{t}\right)<\left(\lambda_{t}-\right. \\
\left.\theta_{t}\right)\left(1-\hat{\varphi}_{t} / k_{t}\right)\end{array}$ & $\begin{array}{c}m\left(k_{t}\right)(1- \\
\left.\hat{\kappa}_{t} / k_{t}\right)>\left(\lambda_{t}-\right. \\
\left.\theta_{t}\right)\left(1-\hat{\varphi}_{t} / k_{t}\right)\end{array}$ & Never \\
\hline
\end{tabular}

TABle 2 Summary Statistics of InTernational Business Travel in the US, UK AND AUSTRALIA IN 1997

\begin{tabular}{lccc}
\hline & $\begin{array}{c}\text { Business travellers } \\
\text { as a \% of domestic } \\
\text { employment }\end{array}$ & $\begin{array}{c}\text { Equivalent workers } \\
\text { as a \% of domestic } \\
\text { employment }\end{array}$ & $\begin{array}{c}\text { Ratio of skilled } \\
\text { among travellers vs. } \\
\text { domestic employment }\end{array}$ \\
\hline $\begin{array}{l}\text { United States } \\
\text { Outgoing }\end{array}$ & & & \\
Incoming & 6.1 & 1.9 & 2.32 \\
\hline United Kingdom & 5.5 & 0.9 & 2.27 \\
Outgoing & & & \\
Incoming & 29.9 & 0.7 & 2.21 \\
\hline Australia & 26.4 & 0.5 & \\
Outgoing & 5.9 & 0.5 & \\
Incoming & 4.9 & 0.3 & \\
\hline $\begin{array}{l}\text { Source: US: Anderson (2002 - Table 1); UK: ONS (Travel Trends, 1999 - Tables 2.05 and 3.05), IATS } \\
\text { (1988 - skill composition), Eurostat (2002 - Labour Force Survey); Australia: Australian Bureau of }\end{array}$ \\
Statistics (2002 - Overseas Arrivals and Departures ABS 3401.0) and Tani (2003 - skill composition).
\end{tabular}


Table 3 The EfFect of International Business Travel ON GDP GROWTH IN 1997.

\begin{tabular}{lccc}
\hline & $\begin{array}{c}\text { Embodied } \\
\text { Effect }\end{array}$ & $\begin{array}{c}\text { Disembodied } \\
\text { Effect }\end{array}$ & $\begin{array}{c}\text { Net Effect } \\
\text { on GDP Growth }\end{array}$ \\
\hline US & $-0.275 \%$ & $+0.467 \%$ & $+0.192 \%$ \\
UK & $-0.053 \%$ & $+0.200 \%$ & $+0.147 \%$ \\
Australia & $-0.050 \%$ & $+0.130 \%$ & $+0.080 \%$ \\
\hline
\end{tabular}


Figure1 Gross Flows OF Equivalent WORKERS AND Multi-FaCtor Productivity FOR AUSTRALIA (1977-2001)

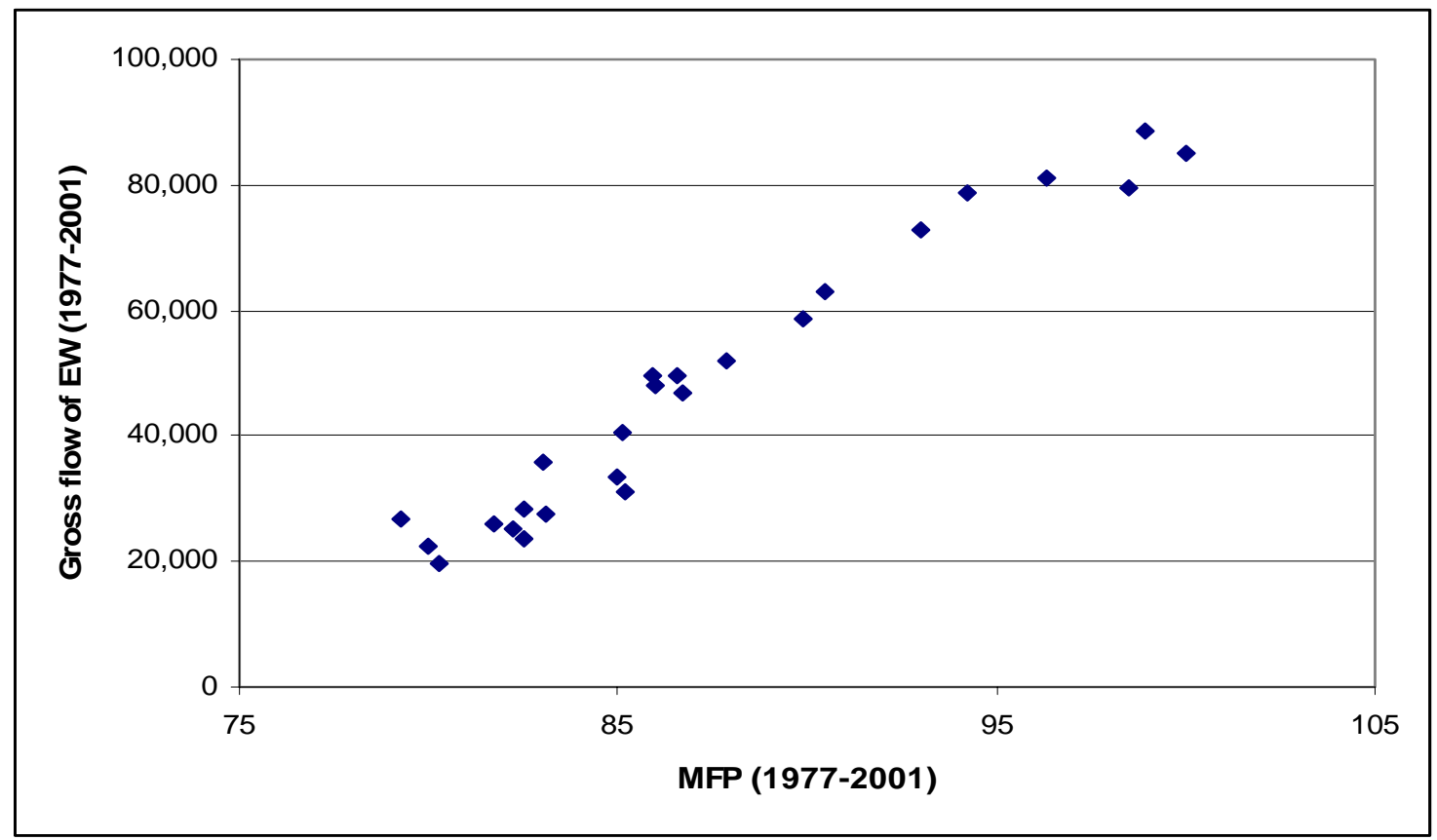

Source: MFP: Australian Bureaus of Statistics (2002): "Multifactor productivity Australia” cat.1360). Equivalent workers: author's calculation based on Department of Immigration, Multicultural and Indigenous Affairs (DIMIA): Overseas Arrivals and Departures, various years

Correlation coefficients: .9744 (level) and .4029 (change)

\section{Figure 2 The GrowTh EFFEct OF TEMPORARY Migration}

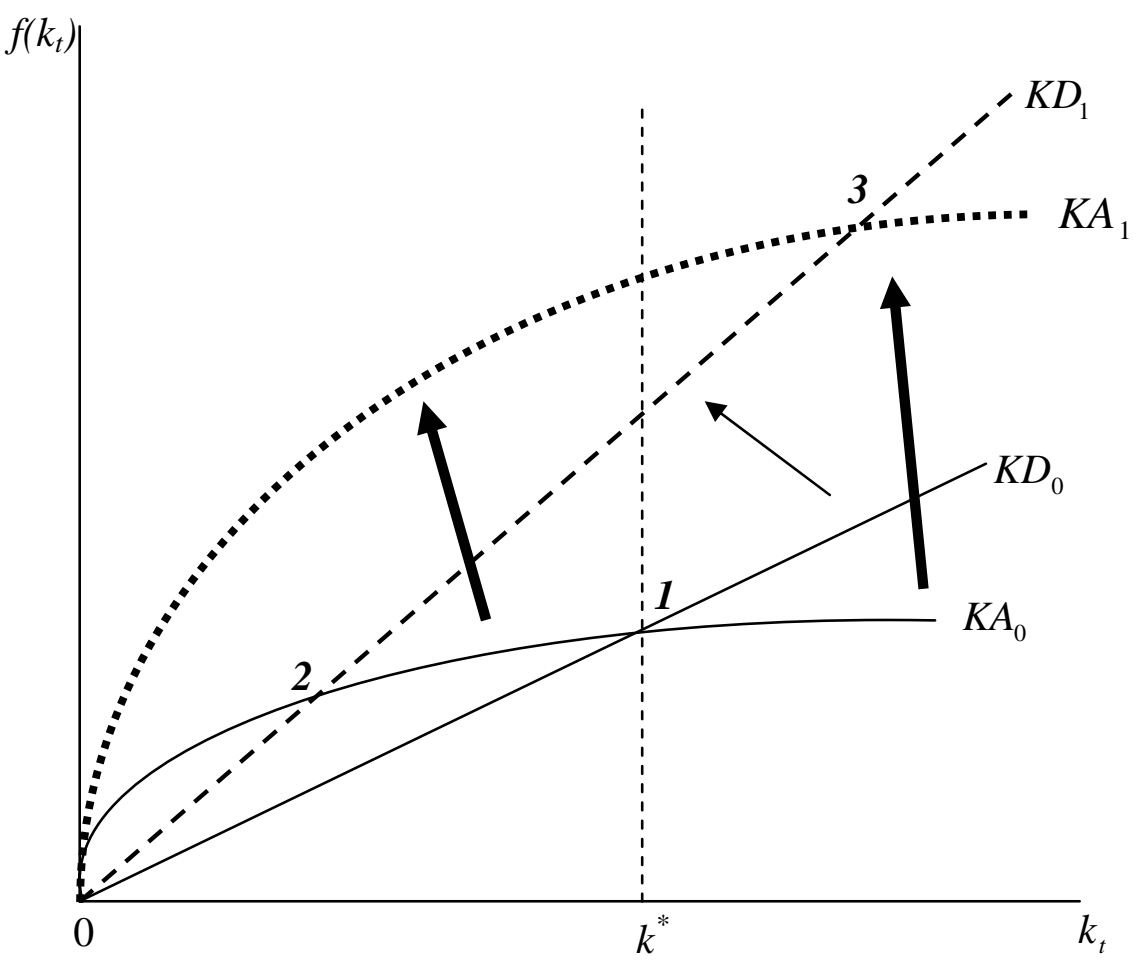

